\title{
UNIDADE, DIVERSIDADE E A INVENÇÃO DOS ÍNDIOS: ENTRE GABRIEL SOARES DE SOUSA $E$ FRANCISCO ADOLFO DE VARNHAGEN ${ }^{*}$
}

\author{
John Manuel Monteiro \\ Departamento de Antropologia - IFCH-Unicamp
}

\section{Resumo}

Este artigo analisa a descrição dos índios feita por Gabriel Soares de Sousa em dois contextos distintos: o do período no qual foi escrito (década de 1580) e o do período em que foi editado integralmente pela primeira vez por F. A. Varnhagen (meados do séc.XIX). O texto procura mostrar a maneira pela qual as descrições detalhadas e as classificações esquematizadas do autor quinhentista foram incorporadas enquanto fatos etnográficos pelas primeiras gerações de historiadores nacionais.

\section{Abstract}

This article analizes Gabriel Soares de Sousa's description of Indians in two distinct contexts: that of the period in which he wrote his work (1580s) and that of the period in which the first complete edition was published by F. A. Varnhagen (mid-nineteenth century). The author seeks to show how Sousa's detailed descriptions and schematic classifications became incorporated as ethnographic facts by the first generation of historians in Brazil after it became a nation.

\section{Pallavras-Chave}

Gabriel Soares de Sousa • Francisco Adolfo de Varnhagen • Índios Tupinambás

\section{Keywords}

Gabriel Soares de Sousa • Francisco Adolfo de Varnhagen • Tupinambá Indians

\footnotetext{
* Uma versão anterior deste texto foi publicada na Hispanic American Historical Review, 80:4, nov. 2000, pp. 697-719, com o título “The Heathen Castes of Sixteenth-Century Portuguese America: Unity, Diversity, and the Invention of the Brazilian Indians". Trechos da primeira parte foram publicadas no texto de divulgação "A Descoberta dos Índios", D. O. Leitura, São Paulo, Ano 17, no. 1, maio de 1999, suplemento 500 Anos de Brasil, pp. 6-7. Agradeço a Manuela Carneiro da Cunha e Stuart Schwartz, que comentaram a versão preliminar que foi apresentada na reunião anual da American Historical Association, janeiro de 2000.
} 
s portugueses alcançaram o litoral sul-americano pela primeira vez em abril de 1500, porém foi apenas no último quartel do século XVI que começaram a produzir relatos sistemáticos com o intuito de descrever e classificar as populações indígenas. Excetuando-se a sumária História da província de Santa Cruz, de Pero Magalhães Gândavo, impressa em Lisboa em 1576, e algumas cartas jesuíticas amplamente disseminadas na Europa em diversas línguas, os textos portugueses mais significativos permaneceram inéditos por séculos ${ }^{1}$. Tanto o rico tratado descritivo de Gabriel Soares de Sousa, considerado por muitos como o mais importante dos relatos quinhentistas, quanto os escritos do jesuíta Fernão Cardim circularam apenas em cópias manuscritas e, provavelmente, só começaram a ter um grande impacto a partir do século XIX. Ainda assim, o Tratado Descritivo - título posteriormente atribuído à obra, na verdade constituída por dois textos distintos - de Soares de Sousa, bem como os Tratados da Terra e Gente do Brasil, uma compilação da obra de Cardim, proporcionam claros indícios das percepções e imagens acumuladas ao longo do século XVI pelos portugueses no que diz respeito a um universo indígena que se apresentava tão vasto e variado quanto incompreensível ${ }^{2}$.

Este artigo enfoca os escritos de Gabriel Soares de Sousa em dois momentos distintos: primeiro, dentro do contexto histórico do final do século XVI e, segundo,

\footnotetext{
${ }^{1}$ Ao que consta, Gândavo era gramático, tendo publicado um manual de ortografia em 1574. Não se sabe muito sobre a sua estada no Brasil - alguns autores duvidam que ele tenha mesmo colocado o pé na América. Sua História da Província de Santa Cruz a que vulgarmente chamamos Brasil, impressa por Antonio Gonçalves com dedicatória de Camões, foi republicado junto com um manuscrito anterior, denominado "Tratado da Terra do Brasil” (Gândavo 1980 [1576]).

${ }^{2}$ A obra do padre Cardim, Tratados da Terra e da Gente do Brasil, título esse atribuído no século XX, na verdade compreende três textos distintos: Do Clima e Terra do Brasil e de algumas coisas notáveis que se acham na terra como no mar (uma descrição da flora e fauna), Do Princípio e Origem dos Índios do Brasil e de seus costumes, adoração e cerimônias (descrevendo os costumes e a diversidade dos índios), e a Narrativa Epistolar de uma Viagem e Missão Jesuítica (um registro da prolongada viagem do visitador jesuíta Cristóvão de Gouveia pelo Brasil entre 1583 e 1590). Os primeiros dois textos foram publicados em inglês por Samuel Purchas em 1625, porém a autoria foi atribuída erroneamente a um outro jesuíta. Sobre Cardim, ver a introdução e notas de Ana Maria de Azevedo à edição mais recente (Cardim 1997 [1583-90]), bem como o excelente estudo de Charlotte de Castelnau-L'Estoile (2000).
} 
no contexto historiográfico do século XIX, quando suas descrições detalhadas e suas classificações esquematizadas foram absorvidas na qualidade de fatos etnográficos pelas primeiras gerações de historiadores nacionais. Um dos problemas que isso apresenta reside na tendência dos historiadores projetarem para a data emblemática de 1500 - às vésperas do descobrimento - um retrato da diversidade indígena e das relações interétnicas que na verdade se consolidou mais tarde, já refletindo as profundas transformações que atingiram muitas das sociedades ao longo do litoral. Ainda assim, a semelhança de outras tradições historiográficas nas Américas, tanto os relatos em si quanto a sua interpretação posterior pelos historiadores buscavam estabelecer uma imagem estática de sociedades prístinas, como se não tivessem sido atingidos pelo contato com os europeus. Ademais, esta abordagem tende a elidir o papel de atores e de unidades políticas indígenas em resposta à expansão européia, papel esse que foi de suma importância para a articulação das configurações étnicas que na bibliografia convencional sempre aparecem como povos "originais", atemporais e imutáveis, pelo menos até que o contato com os europeus levou à sua dilapidação e, em muitos casos, sua destruição por completo. Avanços recentes nos estudos etno-históricos, no entanto, vêm minando estas perspectivas arraigadas desde há muito, introduzindo uma nova conjugação entre pesquisa documental e perspectivas antropológicas para produzir um renovado retrato das respostas ativas e criativas dos atores indígenas que, apesar de todas as forças contrárias, conseguiram forjar espaços significativos na história colonial, de modo que não é mais admissível omitilos do registro histórico ${ }^{3}$.

\section{Gabriel Soares de Sousa, Etnógrafo}

Em 1587, o senhor de engenho e sertanista português Gabriel Soares de Sousa empreendeu a longa viagem de Salvador a Madri, com o intuito de granjear o apoio

\footnotetext{
${ }^{3}$ Uma ótima discussão desta questão com respeito ao Caribe encontra-se em Sued Badillo (1995). Veja-se, também, Sider (1994), Boccara (1999) e Whitehead (1993a e 1993b), todos enfocando o contexto de transformação nas primeiras relações entre europeus e indígenas em diferentes partes das Américas. Especificamente no que diz respeito ao Brasil, as novas perspectivas estão representadas em Carneiro da Cunha (1992).
} 
régio a seu projeto de devassar o vasto sertão em busca de minas de prata. Para se credenciar junto à coroa, apresentou três manuscritos ao Dom Cristóvão de Moura, oferecendo informações preciosas e perspicazes sobre a terra, a gente e a história das colônias portuguesas que brotavam na América ${ }^{4}$. O primeiro texto, intitulado Roteiro Geral, com largas informações de toda a costa do Brasil, proporcionou uma descrição sucinta do litoral desde a "terra dos Caribes", ao norte do rio Amazonas, até o estuário do Prata. O segundo e seguramente o mais importante texto é o Memorial e Declaração das Grandezas da Bahia de Todos os Santos, de sua fertilidade e das notáveis partes que tem, uma descrição pormenorizada da topografia, das plantas, da fauna e das populações nativas da Bahia, um texto tão rico e evocativo em seus detalhes que é considerado por muitos como a maior obra sobre o Brasil escrita no século XVI ${ }^{5}$. Finalmente, o terceiro texto constituiu-se numa pesada invectiva contra os jesuítas da Bahia, no qual se criticava os missionários não apenas pelas suas atividades supostamente gananciosas, mas também e sobretudo pela interferência dos padres no que tocava à mão-de-obra indígena. Bastante contrastante em relação aos outros textos, este ataque aos jesuítas proporciona uma visão mais clara dos contextos histórico e político nos quais Gabriel Soares de Sousa construiu as suas impressões dos Tupinambá ${ }^{6}$.

Se os relatos de Soares de Sousa têm sido amplamente utilizados desde o século XIX na consolidação de uma tradição de estudos tupis no Brasil, são relativamente poucos os estudos sobre o autor propriamente dito ou sobre as condições nas quais ele conduziu as suas observações. A bem da verdade, pouco se sabe da vida do autor

\footnotetext{
${ }^{4}$ De acordo com Dauril Alden (1996: 87-88, 480), D. Cristóvão de Moura (1538-1613) teve um papel de relevo nesta fase inicial da União Ibérica, como “an ignoble Portuguese quisling in Philip's pay”. ${ }^{5}$ Por exemplo, Rodrigues (1979: 439) refere-se aos textos como "a enciclopédia do século XVI, o maior livro que se escreveu sobre o Brasil dos quinhentos".

${ }^{6}$ Serafim Leite, S.J., o mais importante historiador jesuíta do Brasil, desenterrou uma cópia deste documentos no arquivo da ordem em Roma e a publicou sob o título "Capítulos de Gabriel Soares de Sousa contra os Padres da Companhia de Jesus que residem no Brasil" (Soares de Sousa 1940 [1587]), seguindo o conselho do historiador Sérgio Buarque de Holanda. Leite, no entanto, editou este documento um pouco a contragosto, conforme se pode inferir do prefácio, onde ele rotula o texto como "o documento mais antijesuítico" que se escreveu sobre o Brasil. Deve-se observar, ainda, que o exemplar do Arquivo do Jesuítas não é o original, sendo uma cópia aliás enriquecida pelas respostas escritas por uma comissão de padres a cada "capítulo" e intercaladas ao texto.
} 
além daquilo que se encontra em seus escritos, acrescidos do testamento que ele redigiu em 1584, posteriormente reproduzido por Francisco Adolfo de Varnhagen em sua edição crítica do texto ${ }^{7}$. Nascido em Portugal em data ignorada pelos historiadores, Gabriel Soares de Sousa partiu para o além-mar no início de 1569, possivelmente com destino às cobiçadas minas de Monomotapa, na África Oriental, integrando a poderosa frota comandada por Francisco Barreto, antigo governador da Índia, que pretendia expulsar os muçulmanos daquela região e tomar posse das minas $^{8}$. Não se sabe exatamente porque resolveu desembarcar em Salvador quando a frota fez escala, ao invés de seguir para o Estado da Índia, destino de outros escritores de talento contemporâneos seus. Junto com seu irmão João Coelho de Sousa, Gabriel Soares de Sousa se radicou no Brasil, estabelecendo um engenho no rio Jiquiriçá, próximo a Jaguaripe, uma zona açucareira em franca expansão ao sul do Recôncavo. Depois de receber algumas cartas geográficas junto com amostras de pedras preciosas provenientes do sertão, objetos estes legados pelo seu falecido irmão, Gabriel Soares resolveu partir para a corte filipina em 1586 em busca de favores e mercês. Enquanto aguardava audiência, concluiu os textos sobre o Brasil, os quais certamente ajudaram ele a atingir seu objetivo principal de assegurar concessões para procurar e eventualmente explorar minas de prata no sertão, recebendo em 1590 a nomeação de Capitão-mor e Governador da Conquista e Descobrimento do Rio São Francisco. Ao assumir este novo cargo, voltou à América na urca flamenga Abraão, que buscava uma carga de açúcar e pau brasil. A embarcação naufragou na barra do rio Vazabarris, no Sergipe, e grande parte dos equipamentos foi perdida no desastre. Ao chegar em Salvador após uma boa caminhada, Soares de Sousa reorganizou a expedição graças ao patrocínio do governador D. Francisco de Sousa e logo partiu para o sertão do São Francisco. Contudo, as minas que já haviam se mostrado tão inatingíveis para seu irmão e outros exploradores

\footnotetext{
${ }^{7}$ Utilizo aqui a edição de 1971, com o texto estabelecido e anotado por Francisco Adolfo de Varnhagen. Foi esta baseada na edição de 1851, considerada como a mais correta. Vale dizer que esta obra se ressente de uma nova edição crítica, algo na linha do bom trabalho executado por Ana Maria de Azevedo com os textos de Cardim.

${ }^{8}$ Sobre a expedição de Barreto, ver Newitt (1995: 56-57).
} 
não foram alcançadas. Gabriel Soares de Sousa faleceu pouco depois da partida da expedição, quando o grupo já se encontrava fundo no sertão, junto às cabeceiras do rio Paraguaçu. A sua ossada foi remetida a Salvador para ser enterrada na igreja beneditina sob uma lápide que rezava "Aqui jaz um pecador".

As versões relatando a morte de Soares de Sousa são discrepantes, porém apontam para a convergência entre fato e fantasia, o que ajuda a entender o contexto que informava o texto que ele escreveu sobre os índios da Bahia. De acordo com o frei Vicente do Salvador, Soares de Sousa faleceu próximo ao lugar onde havia morrido seu irmão, após cair doente "por as águas serem ruins e os mantimentos piores, que eram cobras e lagartos" (Salvador 1982 [1627]: 262-263). Outro escritor, Pedro Barbosa Leal, forneceu uma versão alternativa, sublinhando outros perigos do sertão. Certa noite, eclodiu "uma grande pendência" entre o "gentio manso e o do sertão", recém introduzido ao acampamento. Procurando apaziguar as partes, Soares de Sousa "saiu de sua barraca e a golpes de espada, maltratou a uns e a outros", o que redundou na fuga de todos os índios da expedição, deixando os exploradores sem eira nem beira no miolo daquele "deserto". Todos teriam morrido, salvo um mineiro prático, Marcos Ferreira, que contou a história ${ }^{9}$.

Sem entrar no mérito de sua veracidade, pode-se afirmar que este relato revela o sentido duplo da expedição, que aliava interesses mineradores e escravizadores, o que iria permanecer como uma das principais características das expedições para o sertão por muitos anos ${ }^{10}$. Assim, a economia açucareira, o sertanismo e a escravidão indígena proporcionaram o contexto para a elaboração do Roteiro e do Memorial de Gabriel Soares de Sousa. Com certeza, estes textos refletem a longa convivência entre o autor e os índios, durante as suas experiências de senhor de engenho e de sertanista, atividades complementares nesta época em que a base do trabalho escravo era composta de índios egressos dos sertões circunvizinhos ${ }^{11}$. Gabriel Soares também conhecia os integrantes nativos dos aldeamentos do Recôncavo, que figuravam entre

\footnotetext{
${ }^{9}$ Estas versões são resumidas em Franco (1954: 397-398).

${ }^{10}$ Sobre estas expedições, ver Monteiro (1994), sobretudo capítulo 2.

${ }^{11} \mathrm{O}$ contexto histórico deste período vem muito bem detalhado e documentado em Schwartz (1988: capítulos 2 e 3 ).
} 
os auxiliares que acompanhavam este português em suas jornadas para o sertão e que proporcionavam uma fonte de mão-de-obra na faina açucareira. Neste sentido, as informações históricas e descritivas apresentadas neste relato foram produzidas neste contexto colonial, sendo que os próprios "informantes" do autor eram "índios coloniais", por assim dizer. O autor tomou o cuidado de explicitar isto, baseandose nas "informações que se têm tomado dos índios muito antigos..." (Soares de Sousa 1971 [1587]: 299).

Isto é significativo quando se considera que grande parte do relato sobre os índios Tupinambá foi escrito em tom de memória, como se a integridade e a independência deste povo fossem algo já do passado. De fato, um dos principais objetivos discursivos do autor foi exatamente o de justificar a dominação portuguesa, colocando-a numa sequência histórica de ciclos de conquista, a começar pela mais antiga "casta de gentio", os Tapuia. Num passado remoto, os Tapuia "foram lançados fora da terra da Bahia e da vizinhança do mar por outro gentio seu contrário", um grupo tupi chamado Tupinaé, "que desceu do sertão, à fama da fartura da terra e mar desta província". Após muitas gerações, "chegando à notícia dos tupinambás a grossura e fertilidade desta terra", este novo grupo invadiu as terras dos Tupinaé, "destruíndolhes suas aldeias e roças, matando aos que lhe faziam rosto, sem perdoarem a ninguém, até que os lançaram fora das vizinhanças do mar". Ao concluir este capítulo do Memorial, Soares de Sousa observou: "[A]ssim foram [os tupinambás] possuidores desta província da Bahia muitos anos, fazendo guerra a seus contrários com muito esforço, até a vinda dos portugueses a ela; dos quais tupinambás e tupinaés se têm tomado esta informação, em cuja memória andam estas histórias de geração em geração" (Soares de Sousa 1971 [1587]: 299-300). Derrotados, parecia restar aos Tupinambás a memória de sua antiga grandeza ${ }^{12}$.

\footnotetext{
${ }^{12}$ Pode-se dizer, é claro, que Gabriel Soares buscava apenas elaborar uma sequência histórica de conquistas na qual a dominação portuguesa se encaixava de modo harmonioso. Mas a ascensão dos Tupinambá no litoral baiano na verdade proporciona um dos eventos mais significativos da história pré-colonial do Brasil, ao coincidir com a emergência de outros grupos tupis e guaranis ao longo do litoral atlântico. Sobre a "expansão" ou "migração" tupi, debate aliás antigo na etnologia e arqueologia brasileiras, ver o artigo de Francisco Noelli (1996), com comentários de Eduardo Viveiros de Castro e Greg Urban.
} 
Ao tratar dos índios em seu texto, a primeira tarefa que enfrentava Gabriel Soares de Sousa foi o de conferir algum sentido à intrigante sociodiversidade que tornava o litoral brasileiro tão difícil para descrever ${ }^{13}$. A exemplo de vários outros autores quinhentistas, Soares de Sousa estabeleceu de início uma grande divisão entre duas categorias maiores, a de Tupi e Tapuia. Se os Tupinambá da Bahia, descritos em detalhes por vezes saborosos, proporcionaram o modelo básico para a discussão da sociedade tupi, mostrava-se bem mais vaga a caracterização dos Tapuia. "Como os tapuias são tantos e estão tão divididos em bandos, costumes e linguagem, para se poder dizer deles muito, era de propósito e devagar tomar grandes informações de suas divisões, vida e costumes; mas, pois ao presente não é possível..." (Soares de Sousa 1971 [1587]: 338). Fiando-se basicamente naquilo que seus informantes tupis lhes passavam, escritores coloniais como Gabriel Soares costumavam projetar os grupos tapuias como a antítese da sociedade tupinambá, portanto descrevendo-os quase sempre em termos negativos.

Ainda assim, em sua descrição dos Aimoré no Roteiro geral, o autor introduziu uma variante interessante, sugerindo que as diferenças básicas na vida e nos costumes desses índios possuíam fundamentos históricos:

Descendem estes aimorés de outros gentios a que chamam tapuias, dos quais nos tempos de atrás se ausentaram certos casais, e foram-se para umas serras mui ásperas, fugindo a um desbarate, em que os puseram seus contrários, onde residiram muitos anos sem verem outra gente; e os que destes descenderam, vieram a perder a linguagem e fizeram outra nova que se não entende de nenhuma outra nação do gentio de todo este Estado do Brasil (Soares de Sousa 1971 [1587]: 78-79).

Se o autor foi bem sucedido ao montar uma descrição bastante detalhada dos costumes bárbaros dos Aimoré, Soares de Sousa reconhecia as limitações de sua apresentação, inclusive deslizando próximo à classificação destes índios como não

\footnotetext{
${ }^{13}$ Este dilema foi compartilhado pelo Gabriel Soares de Sousa com vários outros escritores quinhentistas, que buscavam conciliar aquilo que de fato testemunharam com as imagens dos povos do Novo Mundo que circulavam nos textos e gravuras da época. Veja-se a discussão em Carneiro da Cunha (1990), oferecendo um estimulante contraste entre as visões francesa e portuguesa.
} 
humanos, uma vez que "[c]omem estes selvagens carne humana por mantimento, o que não tem o outro gentio que a não com senão por vingança de suas brigas e antiguidade de seus ódios". Concluindo, o autor sublinhava a diferença desta "casta" das demais, por serem "tão esquivos inimigos de todo o gênero humano" (Soares de Sousa 1971 [1587]: 79-80).

Ao estabelecer categorias básicas para diferentes segmentos da população indígena, Gabriel Soares buscou várias referências distintas. A principal abordagem residia no contraste com as instituições européias, descrevendo as sociedades indígenas a partir daquilo que lhes faltava. Lançando mão de uma frase amplamente disseminada pelo gramático Pero de Magalhães Gândavo na década anterior, Gabriel Soares apresentava uma variante para o ditado sem fé, sem lei, sem rei. Apesar de impressionado pela "graça" da língua tupi, o autor observou que "faltam-lhes três letras do ABC, que são F, L, R grande ou dobrado". A primeira letra, “f”, referia-se à fé, indicando que os Tupinambá não possuíam religião alguma e, pior ainda, "nem os nascidos entre os cristãos e doutrinados pelos padres da Companhia têm fé em Deus Nosso Senhor". Continuando, Soares de Sousa explicou que eles não pronunciavam a letra "l" porque "não tem lei alguma que guardar" e que "cada um faz lei a seu modo e ao som da sua vontade". Finalmente, a ausência da letra " $r$ " denotava a falta de um "rei que os reja" e que não "obedecem a ninguém, nem ao pai o filho, nem o filho ao pai" (Soares de Sousa 1971 [1587]: 302). Oscilando entre a inconstância e a insubordinação, os índios de Gabriel Soares de Sousa mostravam-se pouco promissores enquanto súditos, apesar de que, paradoxalmente, era nessa condição que a maioria dos índios que ele conheceu vivia ${ }^{14}$.

Para além do binômio Tupi-Tapuia, surgiram outros pares de oposição com a função de introduzir alguma ordem numa situação às vezes confusa e imprevisível. O contexto colonial produziu outras distinções importantes, como a oposição entre povoado e sertão, o que representava mais do que uma referência espacial pois, na verdade, delimitava dois universos distintos, um ordenado pela lei e pelo governo, o outro livre de tais constrangimentos - sem fé, nem lei, nem rei, enfim. Pode-se

\footnotetext{
${ }^{14}$ Uma reinterpretação bastante criativa da "inconstância", vista como muito mais do que uma simples projeção européia, encontra-se em Viveiros de Castro (1992).
} 
vislumbrar um bom exemplo desta diferença na experiência dos sertanistas mamelucos, que transitavam entre a ordem rígida do povoado colonial e a liberdade desenfreada do sertão ${ }^{15}$. A distinção entre índios cristãos e gentios proporcionava uma outra divisão crucial, ainda que eivada de implicações ambíguas. Para além de suas origens bíblicas, o termo gentio, com efeito, ganhou força como uma categoria intermediária no campo da diversidade religiosa que adquiria novos contornos com a expansão européia. Os portugueses quinhentistas usavam este termo tanto para descrever hinduístas no subcontinente asiático, com suas elaboradas tradições religiosas, quanto para designar populações africanas e sul-americanas, consideradas como destituídas de qualquer religião. Após um certo tempo, no entanto, o contexto semântico passou a sublinhar a distinção entre nativos convertidos para o catolicismo e aqueles não convertidos - gentios neste caso seriam convertidos potenciais, por assim dizer. Em seu Roteiro geral, Gabriel Soares de Sousa expressou esta distinção, apesar de se mostrar um tanto cético quanto à eficácia da conversão. No capítulo sobre Garcia d'Ávila, o autor fez menção da aldeia jesuítica de Santo Antônio, habitada por “índios forros tupinambás” que, a despeito da sua conversão, "é este gentio tão bárbaro que até hoje não há nenhum que viva como cristão" (Soares de Sousa 1971 [1587]: 70).

Esta observação ganhou um reforço mais agudo nos Capítulos contra os Padres. Se os primeiros missionários tiveram um êxito fenomenal na conversão, batizando "aos milhares cada dia", este êxito se mostrou ilusório, uma vez que "assim com facilidade se faziam cristãos, com ela mesma se tornavam a suas gentilidades, e se foram todos para o sertão, fugindo da sua doutrina" (Soares de Sousa 1940 [1587]: 370). Embora não tenha feito menção explícita no texto, é possível que Gabriel Soares estivesse se referindo aos movimentos sociorreligiosos organizados por índios Tupinambá egressos das aldeias missionárias ou fugidos dos empreendimentos coloniais, com destaque para a Santidade que grassava na época nos arredores de Jaguaripe, próxima portanto ao engenho do próprio Gabriel Soares ${ }^{16}$. Mas o autor certa-

\footnotetext{
${ }^{15}$ Veja-se, por exemplo, as declarações do mameluco Tomacaúna perante o visitador do Santo Ofício, em Vainfas (1997). O mesmo autor traz uma abordagem bastante inovadora dos mamelucos em obra anterior (Vainfas: 1995, capítulo 6).

${ }^{16}$ Vainfas (1995) proporciona a análise mais penetrante deste movimento, que também é o objeto de um artigo recente (Metcalf 1999), cujo objetivo é inserir a santidade num contexto mais amplo de "catolicismo folk messiânico".
} 
mente também conhecia outras formas de resistência - o que ele considerava uma propriedade natural dos índios e não algo vinculado à condição colonial - inclusive as migrações em massa tais como aquela descrita por Anchieta na mesma década de 1580 , registrada mediante a fala de um principal:

Vamo-nos, vamo-nos antes que venham estes portugueses (...) não fugimos da Igreja nem de tua companhia porque, se tu quiseres ir conosco, viveremos contigo no meio desse mato ou sertão ... Mas estes portugueses não nos deixam estar quietos, e se tu vês que tão poucos que aqui andam entre nós tomam nossos irmãos, que podemos esperar, quando os mais vierem, senão que a nós, e as mulheres e filhos farão escravos? (Carta de Anchieta apud Fernandes 1948: 36).

Se os Tupinambá representavam, até certo ponto, uma categoria unificadora do ponto de vista linguística e cultural, coube aos escritores quinhentistas explicar as pronunciadas disputas entre diferentes segmentos dos Tupi. Ao introduzir os Potiguar no Roteiro geral, Gabriel Soares encontrou dificuldades em traçar alguma distinção entre eles e os Tupinambá: "Falam a língua dos tupinambás e caetés; têm os mesmos costumes e gentilidades ... Cantam, bailam, comem e bebem pela ordem dos tupinambás" (Soares de Sousa 1971 [1587]: 54-55). Mais adiante, ao diferenciar os Tupiniquim dos Tupinambá, o autor introduziu um interessante paralelo: "E ainda que são contrários os tupiniquins dos tupinambás, não há entre eles na língua e costumes mais diferença da que têm os moradores de Lisboa dos da Beira” (Soares de Sousa 1971 [1587]: 88). Já no Memorial, ao retomar a descrição dos Tupinaé, Gabriel Soares acrescentou uma ligeira alteração no paralelo, declarando que a língua deles era tão diferente da dos Tupinambá quanto a diferença entre Douro e Minho e Lisboa, ou seja, os Tupinambá falavam um dialeto mais polido. Ao aprofundar sua explicação deste paradoxo de afinidade e diferença, o autor especulou que "pelo nome tão semelhante destas duas castas de gentio se parece bem claro que antigamente foi esta gente toda uma, como dizem os índios antigos desta nação [Tupinambá]". O motivo da divisão é que "têm-se por tão contrários uns dos outros que se comem aos bocados, e não cansam de se matarem em guerras, que continuamente têm" (Soares de Sousa 1971 [1587]: 332-333).

Cabe um breve comentário sobre o uso do termo "casta" para descrever os diferentes grupos indígenas. Vários textos quinhentistas classificavam as populações do litoral sul-americano como "castas" distintas, uma apropriação direta da termi- 
nologia empregada ao longo da costa sul-asiática e amplamente disseminada através de relatos tão antigos quanto os de Duarte Barbosa e Tomé Pires ${ }^{17}$. Ao que parece, esta literatura oriental não era estranha a Soares de Sousa, mesmo porque em certa altura ele estabelece uma comparação explícita entre o uso do fumo entre os ameríndios e o hábito de mascar folhas de bétula na Índia (Soares de Sousa 1971 [1587]: 317). Se vários escritores portugueses referiam-se explicitamente às varnas hindus ao discutir a casta, o termo adquiriu um sentido bem mais genérico, servindo para identificar sociedades ou segmentos sociais enquanto unidades discretas, cada qual possuíndo marcadores culturais próprios, frequentemente enfeixados na noção de "usos e costumes"18. No interior do espaço colonial, contudo, os limites e as características específicas dessas unidades distintas e, muitas vezes, endogâmicas enfrentaram o constante desafio da própria expansão européia, à medida que soldados, comerciantes, colonos e funcionários do estado se envolveram cada vez mais com as sociedades nativas, seja através de alianças matrimoniais ou de arranjos menos formais.

Escrito numa conjuntura de transformações rápidas e decisivas, as quais afetaram de modo particular as populações indígenas mais próximas aos estabelecimentos coloniais, o relato de Gabriel Soares de Sousa sobre os Tupinambá justapôs imagens da grandeza pré-colonial com aquelas da decomposição pós-conquista ${ }^{19}$. Estribadas nos relatos de índios aldeados, escravizados e cristianizados, as descrições nos fornecem uma auto-imagem dos Tupinambá através da lente da situação colonial que os oprimia e, lentamente, os destruía. Ainda assim, estabelecendo um exemplo que seria seguido por etnógrafos num futuro distante, o texto do Memorial buscava abs-

\footnotetext{
${ }^{17}$ Sobre estas fontes, veja-se a obra erudita de Lach (1965) e o excelente ensaio de Curto (1997).

${ }^{18}$ A origem e a variabilidade do termo "casta" constituem aspectos de um longo debate na antropologia e historiografia referentes a Índia. Assim como os modernos, os antigos escritores portugueses geralmente oscilavam entre duas concepções distintas para a organização social hinduísta. O conceito de varna, estabelecido em vários textos sagrados, divide a sociedade em quatro grandes grupos, ordenados hierarquicamente: brâmanes (sacerdotes), kshatriyas (guerreiros), vaishyas (comerciantes) e shudras (trabalhadores). O conceito de jati, por outro lado, refere-se a grupos de filiação, abrangendo um sem-número de "castas" (definidas por categorias de ofício, de grupos tribais e étnicos, entre outras) que, com o advento dos muçulmanos e dos europeus se tornaram cada vez mais fechadas e imóveis. Ver, entre outros, Bayly (1999), sobretudo capítulos 1 e 3, e Perez (1997).

${ }^{19}$ Apresento uma discussão mais detalhada destas transformações em Monteiro (1999).
} 
trair os Tupinambá deste contexto, como se os europeus não os tivessem encontrado. Entretanto, o relato contém muitos elementos que sugerem que este "modo de ser" dos Tupinambá, apesar de reafirmar tradições e estruturas pré-coloniais, também tinha algo a ver com as condições concretas da expansão colonial. Assim, a descrição da vida e dos costumes dos índios foi o produto de construções coloniais não apenas dos portugueses como também dos Tupinambá. Em certo sentido, o Memorial destoava de outros relatos que buscavam projetar a situação de primeiro contato, situação essa que, segundo Neil Whitehead, tinha mais a ver com a "auto-representação dos 'descobridores"' ou conquistadores do que com a efetiva interação envolvendo o autor-observador e seus objetos nativos ${ }^{20}$. Se é verdade que Soares de Sousa se apresentava como descobridor de sertões desconhecidos e da almejada riqueza mineral do mesmo interior, seus objetos nativos configuravam, antes de tudo, índios que já haviam experimentado o contato com os Europeus por um bom tempo.

O próprio autor, visivelmente constrangido ao tratar da presença de muitos mamelucos entre os Tupinambá, acabou reconhecendo que "ainda que pareça fora de propósito o que se contém neste capítulo, pareceu decente escrever aqui o que nele se contém, para se melhor entender a natureza e condição dos tupinambás..." (Soares de Sousa 1971 [1587]: 331). Uma leitura mais atenta deste mesmo capítulo, no entanto, evoca um constante receio que os escritores coloniais cultivavam no que diz respeito à mestiçagem: Gabriel Soares parece ter se preocupado menos com o impacto que os brancos e seus descendentes mestiços poderiam ter sobre os Tupinambá e mais com a terrível possibilidade de que os brancos também podiam tornar-se selvagens.

Ao buscar, deste modo, melhor entender a natureza e condição dos Tupinambá, Gabriel Soares implicitamente captou a necessidade de se reconhecer que as sociedades indígenas encontravam-se imbricadas numa trama histórica, na qual a determinação de identidades específicas se mostrava tão flexível quanto variável ${ }^{21}$. Os Potiguar, Tupiniquim, Tememinó e Tupinaé todos eram Tupinambá num certo

\footnotetext{
${ }^{20}$ Sobre a questão da representação destes “pristine contacts with unspoiled indigenes", ver Whitehead (1995: 55). É interessante observar que este tipo de representação permaneceu como tema constante na literatura e iconografia do contato nos séculos a seguir.

${ }^{21}$ Sobre o contexto colonial para a formação das identidades, ver o artigo instigante de Sider (1994).
} 
sentido, porém no contexto colonial, nitidamente não o eram. Neste sentido, para se entender este "Brasil indígena", é preciso antes rever a tendência seguida por sucessivas gerações de historiadores e de antropólogos que buscaram isolar, essencializar e congelar populações indígenas em etnias fixas, como se o quadro de diferenças étnicas que se conhece hoje existisse antes do descobrimento - ou da invenção - dos índios.

Tão demorado quanto intrincado, o processo inicial de invenção de um Brasil indígena envolveu a criação de um amplo repertório de nomes étnicos e de categorias sociais que buscava classificar e tornar compreensível o rico caleidoscópio de línguas e culturas antes desconhecidas pelos europeus. Mais do que isso, o quadro produzido passou a condicionar as próprias relações políticas entre europeus e nativos, não apenas na medida em que fornecia a base para a elaboração de uma legislação indigenista, mas também porque esboçava um conjunto de representações e de expectativas sobre as quais se pautavam estas relações. Neste sentido, as novas denominações espelhavam não apenas os desejos e as projeções dos europeus, como também os ajustes e as aspirações de diferentes populações nativas que buscavam lidar - cada qual à sua maneira - com os novos desafios postos pelo avanço do domínio colonial.

\section{A Reinvenção dos Tupi: Gabriel Soares de Sousa no Século XIX}

Apesar do grande interesse que poderia ter suscitado na época em que foi elaborada, a obra de Gabriel Soares de Sousa permaneceu inédita por mais de duzentos anos. Ainda assim, a exemplo de tantos outros tratados descritivos e históricos escritos em português sobre o Brasil durante o período colonial, os textos de Soares de Sousa circularam em cópias manuscritas, sendo que diferentes trechos foram parafraseados ou mesmo plagiados por escritores que o sucederam. Ao preparar a edição definitiva desta obra no século XIX, Francisco Adolfo de Varnhagen chegou a identificar 17 cópias distintas em várias bibliotecas e arquivos na Europa, em acervos públicos e privados ${ }^{22}$. De fato, para além dos relatos publicados em várias línguas européias orientados para um público não lusófono, a única obra sobre o Brasil a

\footnotetext{
${ }^{22}$ De acordo com Varnhagen, dentre os vários autores que utilizaram partes do relato de Gabriel Soares para elaborar suas próprias obras, encontram-se Pedro de Mariz, Frei Vicente do Salvador, Simão de Vasconcelos, S.J. e Frei Antônio Jaboatão (Soares de Sousa 1971 [1587]: 13).
} 
ser editada em português durante o século XVI foi a História da província de Santa Cruz, de Pero Magalhães Gândavo, impressa em 1576. Esta ausência de publicações destoava de outras situações coloniais, como a da América Espanhola ou mesmo a dos portugueses na Ásia, que haviam disponibilizado aos leitores europeus uma quantidade considerável de obras impressas, englobando narrativas de conquista e crônicas políticas, bem como descrições minuciosas dos povos e costumes do Oriente.

Relegada ao esquecimento, a obra de Soares de Sousa reapareceu nos primeiros anos do século XIX, inicialmente como parte da vasta e eclética coleção de obras raras e inéditas, organizada pelo frei Veloso e impressa na famosa casa editorial do Arco do Cego em Lisboa. Incompleta, esta primeira edição também deixou de atribuir a autoria a Gabriel Soares. A primeira edição completa de uma cópia dos manuscritos existentes apareceu em 1825, publicada pela Real Academia das Ciências de Lisboa, como parte de seu projeto ambicioso de compilar narrativas de viagem e outros relatos numa ampla coleção sobre as posses ultramarinas portuguesas, inclusive aquela recém separada da metrópole. Adotando o título de Notícias do Brasil, a edição da Academia foi tão mal feita que moveu o então jovem historiador paulista Francisco Adolfo de Varnhagen a escrever um longo e pioneiro exercício de crítica histórica, o que não apenas confirmou a autoria de Gabriel Soares como também apontou para a premente necessidade de uma nova edição crítica e anotada, cotejando criteriosamente as diferentes cópias manuscritas existentes ${ }^{23}$.

O interesse de Varnhagen pelos textos de Gabriel Soares foi muito além desse mero exercício acadêmico. Como membro de destaque do Instituto Histórico e Geográfico Brasileiro, fundado em 1838, Varnhagen situava-se na linha de frente de uma geração de intelectuais e estadistas que enfrentava a tarefa de inaugurar uma tradição histórica nacional. Como parte deste ambicioso projeto coletivo, a Revista Trimestral do Instituto trazia muitos relatos coloniais inéditos, com certa ênfase nas descrições de populações indígenas, sobretudo os Tupi da Costa ${ }^{24}$.

\footnotetext{
${ }^{23}$ Este exercício pioneiro foi publicado pela Academia de Ciências de Lisboa em 1839 com o título de Reflexões Críticas sobre o Escrito do Século XIV [i.e. XVI] impresso com o título de Notícias do Brasil... Cf. Rodrigues (1979: 436).

${ }^{24} \mathrm{Na}$ verdade, alguns dos documentos "coloniais" constituíram exemplos de forjicação escritos no próprio século XIX, como no caso do relato supostamente elaborado por Miguel Ayres de Maldonado, desmascarado pelo trabalho detetivesco de José de Souza Martins (1996).
} 
Com certeza, um dos mais árduos desafios residia na descoberta, recuperação e edição de textos que esboçavam um pano de fundo histórico e etnográfico para os primórdios da civilização brasileira, textos estes em sua maioria soterrados em baixo de camadas de papéis e de poeira em instituições situadas na Europa. Com o intuito de reverter a pesada imagem de uma sociedade escravista atrasada, precariamente civilizada e profundamente miscigenada, os membros do Instituto buscaram conciliar as origens americanas com os princípios civilizadores que guiavam os estados-nação do século XIX ${ }^{25}$. Na falta de ruínas espetaculares de antigas civilizações - problema que foi debatido em algumas das reuniões do Instituto - e enfrentando um conflito acirrado com as populações indígenas contemporâneas, a geração das elites que atingia a maioridade junto com o próprio Imperador começou a esboçar uma mitografia nacional que colocava os nobres, valentes e, sobretudo, extintos Tupi no centro do palco.

A Revista do Instituto não foi o único órgão impresso a empreender esta tarefa, pois muitos relatos copiados em arquivos e bibliotecas em Lisboa, Évora, Madri, Viena e Paris encontraram vazão nas várias revistas literárias e políticas que agitavam a vida intelectual da jovem nação. Neste mesmo período, o desenvolvimento de um conhecimento etnográfico acompanhava uma emergente literatura voltada para temas fundacionais: assim, poetas e romancistas ancoravam sua obra indianista numa familiaridade com a etnografia, ao mesmo tempo em que ecoavam as percepções e temas aprofundados por historiadores e outros estudiosos. A bem da verdade, vários escritores transitavam entre os diferentes gêneros ficcionais e acadêmicos; basta recordar que os principais poetas indianistas também se destacaram como historiadores e etnógrafos. Esta mesma preocupação com uma base documental sólida tornava-se evidente na obra pioneira de Varnhagen, a História Geral do Brasil, cuja edição em múltiplos volumes começou em $1854^{26}$.

Se a História Geral representava o primeiro grande compêndio em português sobre a história do país, ela teve precedentes estrangeiros significativos, sobretudo a History of Brazil de Robert Southey e as obras de Ferdinand Denis. Ambos esses

\footnotetext{
${ }^{25}$ Sobre as origens do Instituto e o projeto historiográfico coletivo daquela geração, ver o excelente artigo de Manoel Luís Salgado Guimarães (1988) e o livro de Schwarcz (1993), sobretudo pp. 91-117. ${ }^{26}$ Sobre Varnhagen, ver Rodrigues (1988: 13-27); Odália (1997); Reis (1997); e, sobretudo, Oliveira (2000).
} 
autores utilizaram diferentes versões manuscritas da descrição que Gabriel Soares de Sousa elaborou a respeito dos Tupinambá, embora nenhum deles tenha identificado corretamente o autor ${ }^{27}$. Nestas obras, os antigos Tupinambá cresceram em estatura e passaram a demarcar um forte contraste entre os índios que ocupavam o litoral sul-americano na gênese da nacionalidade brasileira e aqueles contemporâneos que atrapalhavam a marcha da civilização.

$\mathrm{Na}$ obra de Varnhagen, o papel que os índios desempenhariam nesse projeto estava claramente delimitado desde o início, uma vez que este autor assimilava explicitamente a postura pessimista que Carl Friedrich von Martius propagava. Em 1847, um ensaio escrito por von Martius venceu um concurso promovido pelo Instituto Histórico e Geográfico em torno do tema de "Como se deve escrever a história do Brasil”. Simpático às teorias setecentistas referentes à decadência e decrepitude do homem americano, von Martius considerava as populações indígenas do Brasil como povos que deixariam de existir num futuro bem próximo ${ }^{28}$. "[O] triste e penível quadro", escrevia ele, "que nos oferece o atual indígena brasileiro, não é senão o resíduo de uma muito antiga, posto que perdida história" (Martius 1982 [1845]: 91 92). Este pessimismo se mostrou ainda mais explícito num texto anterior, onde fez a seguinte previsão: "não há dúvida: o americano está prestes a desaparecer. Outros povos viverão quando aqueles infelizes do Novo Mundo já dormirem o seu sono eterno" (Martius 1982 [1838]: 70).

Adotando estes pressupostos, Varnhagen desenvolveu uma profunda "aversão às populações brasileiras" (palavras de seu arquiinimigo João Francisco Lisboa), o que aliás não se limitava às populações indígenas como também se estendia a todas as camadas populares da América portuguesa. Se esta aversão certamente alguma

\footnotetext{
${ }^{27}$ Robert Southey (1810-19) utilizou uma cópia manuscrita do (então) anônimo "Notícias do Brasil", transcrito por um tio de um exemplar em Portugal. Sobre a obra de Southey, ver o clássico estudo de Dias (1974); já Ferdinand Denis (1837), em sua obra geral que faz um resumo de estudos anteriores, possivelmente lançou mão tanto da cópia manuscrita existente na Bibliothèque Nationale de Paris quanto das primeiras edições portuguesas. Sobre Denis, ver o cuidadoso estudo de Rouanet (1991). ${ }^{28}$ Inscrito no concurso em 1843, o texto de von Martius foi publicado na Revista Trimensal em 1845 e recebeu o prêmio em 1847. Uma excelente análise da contribuição de Martius à historiografia e etnologia no Brasil encontra-se em Lisboa (1997).
} 
coisa devia às preferências teóricas do autor, ela pode igualmente ser atribuída à experiência pessoal de Varnhagen ou mesmo à situação política do Império em meados do século XIX, quando várias províncias conduziam guerras não declaradas contra povos indígenas. É provável que Varnhagen já alimentasse sentimentos depreciativos referentes aos índios quando empreendeu uma viagem para o sul da Província de São Paulo em 1840, porém após presenciar de perto o estado de conflito e de medo que predominava na região, consolidou o seu ponto de vista marcadamente negativo. "Confesso", escreveu ele alguns anos mais tarde, "que desde então uma profunda mágoa e até um certo vexame se apoderou de mim, ao considerar que apesar de ter o Brasil um governo regular, em tantos lugares do seu território achavam-se (e acham-se ainda) um grande número de cidadãos brasileiros à mercê de semelhantes cáfilas de canibais" (Varnhagen 1867: 38). De maneira bastante consciente, Varnhagen inscreveu esta aversão aos índios em sua História Geral do Brasil, na qual a sua descrição dos "antigos" Tupi foi capaz apenas de captar, "no triste e degradante estado da anarquia selvagem, uma idéia do seu estado, não podemos dizer de civilização, mas de barbárie e de atraso. De tais povos na infância não há história: há só etnografia" (Varnhagen 1981 [1854] I:30) ${ }^{29}$.

Se esta perspectiva negativa encontrou um lugar seguro na raiz dos estudos históricos brasileiros, ela não constituiu a única perspectiva. De fato, um intenso debate em torno dos índios agitava os círculos intelectuais e políticos do século XIX, onde vozes agressivas como a de Varnhagen encontravam a oposição de tendências mais filantrópicas, sobretudo aquela inspirada em José Bonifácio de Andrada e Silva ${ }^{30}$. Até certo ponto, desde os primórdios do período colonial, o conflito de interesses entre diferentes agentes coloniais criou tensões entre as políticas que buscavam ou assimilar ou excluir as populações indígenas. As mudanças institucionais da década de 1840, que delegaram às províncias a gestão da política indigenista e promoveram o estabelecimento de novas missões capuchinhas, introduziram um novo período

\footnotetext{
${ }^{29}$ Suas observações referentes à viagem para o sul aparecem em Varnhagen (1867: 36-37). Ver, também, Oliveira (2000: 47-48).

${ }^{30}$ Sobre a influência de José Bonifácio's sobre o pensamento indigenista no Brasil, ver sobretudo Carneiro da Cunha (1986); Boehrer (1960); e Hemming (1987).
} 
de tensão. Fosse nos confortáveis recintos das academias ou nas rudes condições do sertão, acirrava-se a disputa entre aqueles que defendiam a "civilização e catequese" dos índios e aqueles parciais ao afastamento ou mesmo extermínio de populações nativas $^{31}$. Não restava dúvida quanto à posição de Varnhagen neste conflito, posição essa que buscava sustentação nas evidências históricas, inclusive no relato de Gabriel Soares de Sousa.

Em suas leituras de fontes quinhentistas, uma das primeiras operações empreendidas pelos historiadores do Império foi a de reconfigurar a dicotomia TupiTapuia, acrescentando um novo eixo temporal à análise. Como vimos, este binômio tornava o problema da diversidade linguística e étnica mais fácil de administrar, tanto para os escritores coloniais quanto para as autoridades da coroa. No contexto do século XIX, ganhou uma nova feição. Os Tupi foram relegados a um passado remoto, quando contribuíram de maneira heróica à consolidação da presença portuguesa através das alianças políticas e matrimoniais. Mas as gerações subsequentes cederam o lugar para a civilização superior, deixando algumas marcas para a posteridade, inscritas nos topônimos, nos descendentes mestiços e na persistência da língua geral que, no século XIX, ainda vigorava entre algumas populações regionais e era cultivada por setores das elites imperiais como a autêntica língua nacional. Nessa ótica do Oitocentos, os Tupi do litoral pareciam ter perecido por completo desde há muito, sendo retratados cada vez mais em tons românticos e nostálgicos, como no quadro emblemático de Rodolfo Amoedo, O Último Tamoio, que mostra um Tupinambá literalmente morrendo na praia e recebendo a extrema unção de um padre capucho, antes de ser levado pelo mar para sempre ${ }^{32}$.

Os Tapuia, por seu turno, situavam-se no pólo oposto, apesar das abundantes evidências históricas que mostravam uma realidade mais ambígua. Retratados no mais das vezes como inimigos e não como aliados - dos portugueses, bem entendido

\footnotetext{
${ }^{31}$ Sobre este assunto, ver Monteiro (1992). O contexto geral para este debate e suas implicações para a política e legislação indigenista está minuciosamente exposto em Carneiro da Cunha (1992). ${ }^{32}$ Exibido pela primeira vez num salon parisiense em 1883, O Último Tamoio faz parte da coleção permanente da Pinacoteca do Estado de São Paulo. Em sua análise da literatura indianista, Graça (1998) defende a idéia de que os poetas e romancistas desenvolveram uma espécie de "poética do extermínio".
} 
- representavam o traiçoeiro selvagem, obstáculo no caminho da civilização, muito distinto do nobre guerreiro que acabou se submetendo ao domínio colonial. Se esta última opção teria custado os Tupi a sua existência enquanto povo, a resistência e recusa dos Tapuia acabaram garantindo a sua sobrevivência em pleno século XIX, mesmo tendo enfrentado brutais políticas visando o seu extermínio. Varnhagen e outros historiadores traduziam as lições da história num discurso que condenava os grupos indígenas contemporâneos, sobretudo os Botocudos no leste, os Kaingang no sul e vários grupos jê do Brasil central. Desta feita, estes grupos adquiriram um duplo estigma: primeiro, como o anti-Tupi nos textos históricos e, segundo, como obstáculos à civilização pelos padrões da época.

Se a tendência predominante estabeleceu um nítido contraste entre o nobre Tupi, ancestrais primordiais dos modernos brasileiros, e os grupos indígenas contemporâneos, representados em termos negativos, Varnhagen destoava um pouco ao traçar semelhanças entre os guerreiros tupinambás, com suas características traiçoeiras e vingativas, e sua contrapartida não-tupi do século XIX. Para tanto, sua leitura dos textos de Gabriel Soares de Sousa foi instrumental, como se pode perceber em seus "comentários", que transitavam livremente entre o século XVI e o XIX. Para Varnhagen, o relato de Gabriel Soares confirmava aquilo que considerava ser o caráter covarde de todos os povos indígenas, o que justificava as represálias violentas por parte de colonos e de autoridades, política essa sancionada pelo historiador em várias ocasiões. Comprimindo as distâncias no tempo e no espaço, Varnhagen tomou o exemplo dos Tupinambá para lembrar aos leitores que "[é] o que ainda sucede com os dos nossos sertões. Os bugres recebem presentes de ferrinhos que no ano seguinte enviam contra o benfeitor mui aguçados, nas pontas de suas flechas; ou assassinam aqueles que, depois de lhes fazer presentes, neles confiam" (Soares de Sousa 1971 [1587]: 386, n. 246).

Em suas notas ao texto de Gabriel Soares, Varnhagen oscilava entre as observações sóbrias e neutras que se esperaria de um cientista da época e os comentários tendenciosos de alguém buscando desqualificar os índios enquanto terríveis selvagens. Até certo ponto, esta oscilação refletia o próprio texto do autor quinhentista que, em sua minuciosa dissecção de todos os aspectos da sociedade tupinambá, também alternava entre uma profunda admiração e uma certa suspeição. Varnhagen tinha plena consciência da enorme contribuição que o texto trazia para a etnologia de sua 
época e chamou a atenção corretamente para várias informações importantes, como aquelas constantes dos capítulos sobre as práticas de nominação e as relações de parentesco. Entretanto, o historiador dificilmente aceitava qualquer aspecto positivo o virtuoso da cultura tupinambá, sempre apontando para os leitores o seu caráter traiçoeiro, sombrio e ignorante. Por exemplo, ao comentar o capítulo que Soares de Sousa escreveu sobre a música, acabou rebaixando mais uma vez os Tupinambá: "Tal é a magia da música e da poesia que a apreciam até os povos sepultados na maior brutalidade" (Soares de Sousa 1971 [1587]: 385, n. 236).

Varnhagen afastou-se ainda mais de um padrão científico em seus comentários sobre a guerra e o canibalismo tupinambá, certamente aspectos dos mais intrigantes que fascinavam todos os autores do século XVI. Ao invés de fazer uma reflexão sobre as informações etnográficas significativas que o texto de Gabriel Soares oferecia, Varnhagen optou por sublinhar a carga negativa do canibalismo, deixando de lado a insistência do autor do Memorial em apontar o conteúdo simbólico das práticas tupis que, como vimos, seriam distintos das práticas dos Aimoré, aliás facilmente traduzidos em Botocudos do século XIX ${ }^{33}$. Ao desqualificar os Tupinambá - e, por extensão, todos os outros índios - Varnhagen com efeito fornecia uma justificativa para a dominação portuguesa, justificativa essa muito distante da narrativa de conquista tecida por Gabriel Soares. A "raça túpica", em sua opinião, estava tão fracionada no início do século XVI que, "a não ter lugar a colonização européia, a mesma raça devia perecer assassinada por suas próprias mãos". A lição valia para o século XIX, pois arrematava Varnhagen: "como quase vai sucedendo nestes matos virgens, em que temos índios bravos, fazendo-se uns aos outros crua guerra" (Soares de Sousa 1971 [1587]: 382, n. 222).

A idéia de que os índios estavam se matando não era, na verdade, muito original. Vários missionários e autoridades régias avançaram argumentos semelhantes para justificar suas ações e fazia parte da postura de intelectuais e políticos do Império como Varnhagen - que promoviam uma política indigenista abertamente agressiva. Mais uma vez em diálogo com o texto de Gabriel Soares, a história e a política con-

\footnotetext{
${ }^{33}$ Sobre o contraste entre o canibalismo tupi e aimoré, veja-se Carneiro da Cunha (1990: 108-109).

${ }^{34}$ Foi nesse sentido que Melo Morais atribuiu, na Revista da Exposição Antropológica de 1882, a "extinção dos índios" às "guerras intestinas (...) fazendo estacionar ou extinguir lentamente as raças indígenas do Brasil” (Revista: 1882, 23-24).
} 
fluíram nos comentários de Varnhagen, que vivamente recomendava a leitura do capítulo 160, sobre "algumas habilidades e costumes dos tupinambás", aos que "sustentam o pouco préstimo do nosso gentio, que por 'filantropia' estamos deixando nos matos tragando-se uns aos outros, e caçando os nossos africanos (a que chamam de 'macacos do chão’ só para os comer!" (Soares de Sousa 1971 [1587]: 384, n. 235).

Em sua leitura de Gabriel Soares, Varnhagen também contribui para o processo de classificação de grupos indígenas em entidades fixas e atemporais, inclusive elidindo as interessantes explicações históricas oferecidas pelo autor quinhentista no que diz respeito às diferenças entre os grupos tupis. Um bom exemplo desta discrepância é o caso Amoipira, um grupo tupi que habitava o rio São Francisco na segunda metade do século XVI. Gabriel Soares descreveu esse grupo como possuidor dos "mesmos costumes e gentilidades" dos Tupinambá, bem como a mesma língua, embora guardando algumas diferenças "em alguns nomes próprios". Descendentes dos Tupinambá, esse grupo afastou-se para o interior frente ao avanço de seus inimigos e adotou o nome "por seu principal se chamar Amoipira" (Soares de Sousa 1971 [1587]: 334-335). Em seu comentário, Varnhagen discordou de Gabriel Soares, substituindo a credibilidade desse autor com uma outra espécie de autoridade etnográfica que se tornou muito popular no decorrer do século XIX: a etimologia tupi-guarani. De acordo com Varnhagen, ao desmembrar o termo em duas palavras constantes do Tesoro de la lengua guarani, do jesuíta seiscentista Antonio Ruíz de Montoya, Amoipira teria o significado de "parentes cruéis" (Soares de Sousa 1971 [1587]: 387, n. 254).

Seria um erro crasso, contudo, afirmar que este historiador do século XIX simplesmente ignorava a dimensão histórica do panorama etnográfico que ele traçava para o Brasil do século XVI. Parcial aos postulados pessimistas de von Martius, que considerava os índios como os descendentes degradados de alguma antiga civilização, a leitura que Varnhagen fez da diversidade étnica entre os Tupi, embora baseada fundamentalmente no relato de Soares de Sousa, sugeria que o fracionamento étnico não era mais do que outro indício do declínio, desintegração e destruição de um grande povo anterior, processo esse desencadeado bem antes da chegada dos portugueses. Varnhagen apenas arranhou esta hipótese em seus comentários ao texto de Gabriel Soares, porém a desenvolveu mais plenamente na História Geral e, de maneira mais contundente, num de seus últimos estudos, L'origine tourainienne des américains tupi-caribes et des ancien égyptiens, obra publicada 
em Viena em 1876. Um dos pontos mais controversos certamente foi aquele que dizia respeito às origens "estrangeiras" dos Tupi, o que distanciava este autor não apenas de Gabriel Soares de Sousa, como também de grande parte de seus contemporâneos. Para a maioria dos escritores oitocentistas, os Tupi representavam os brasileiros mais autênticos e originais, apesar da circulação de teorias sobre migrações intercontinentais que teriam ocorrido num passado tão distante quanto nebuloso. Se Gabriel Soares mostrava-se um tanto impreciso quanto a esta questão, simplesmente afirmando que os Tupi iniciaram o seu movimento rumo ao litoral a partir de algum lugar no remoto sertão, Varnhagen buscou as origens dos Tupi fora mesmo das Américas, chegando a caracterizá-los como um povo invasor. Levou esta idéia a seu ponto máximo em L'origine tourainienne. Exercício meticuloso de filologia e etnologia comparada, L'origine tourainienne busca semelhanças explícitas nas línguas e na cultura material dos Tupi e dos antigos egípcios, os quais teriam sido ambos influenciados por uma civilização centro-asiático anterior ${ }^{35}$. Ao invés de procurar, conforme alguns comentaristas têm sugerido, as origens arianas dos antigos Tupi - estratégia essa compartilhada por outros escritores latino-americanos no século XIX - Varnhagen parece ter perseguido um propósito bem diferente ${ }^{36}$. De fato, ao invés de "branquear" os Tupi, Varnhagen procurou identificar uma remota civilização não-ariana, a partir da qual os índios brasileiros teriam iniciado o seu declínio, num longo processo de decadência e degeneração.

Poucos estudiosos parecem ter levado a sério a tese turaniana no Brasil, porém a idéia de Varnhagen de rebaixar e excluir os índios da história pátria permaneceu firme no pensamento histórico brasileiro por gerações e gerações. Ainda assim, vozes dissonantes surgiram tão logo que saiu publicado a História Geral do Brasil; por

\footnotetext{
${ }^{35}$ Oliveira (2000: 90-100) apresenta uma análise bastante interessante desta obra. Odália (1997: 98 103) também fornece uma discussão estimulante da abordagem comparativa do autor, enfocando mais especificamente sua História Geral.

${ }^{36}$ José Vieira Couto de Magalhães, em seu capítulo sobre “As Línguas Arianas da América” (1975 [1876]: 51-54), refere-se ao estudioso argentino Fidel López, cujos estudos comparados entre sânscrito e quéchua foram publicados em Paris no decorrer dos anos de 1860. Couto de Magalhães também especulava sobre as possíveis afinidades entre o sânscrito e algumas línguas indígenas no Brasil, sobretudo o guaicuru. De acordo com este autor, os antepassados centro-asiáticos dos povos americanos haviam se misturado com alguma "raça ariana" antes da migração para o novo continente.
} 
exemplo, o poeta indianista e historiador Domingos José Gonçalves de Magalhães reagiu de modo virulento num longo ensaio publicado na Revista Trimensal do Instituto, buscando "reabilitar o elemento indígena", como elemento fundamental na composição da população brasileira (Magalhães 1860: 3). Do mesmo modo, já é muito bem conhecida a polêmica entre Varnhagen e João Francisco Lisboa, o liberal maranhense cuja defesa da liberdade e dignidade dos índios estava assentada em seus próprios estudos históricos (Janotti 1977 e Carvalho 1995). Mas para a maioria dos historiadores brasileiros, tornou-se corriqueiro o pressuposto de que o início da história do Brasil significava o fim dos índios.

\section{Conclusão}

Ao remodelar a descrição feita por Gabriel Soares de Sousa dos Tupinambá para situá-la no contexto do século XIX, o historiador pioneiro Francisco Adolfo de Varnhagen afastou este grupo mais ainda do contexto histórico que produziu o mesmo relato. Mais importante, Varnhagen praticamente consolidou o abismo que iria prevalecer nos estudos sobre as populações indígenas até um período bem recente, circunscrevendo os índios a uma distante e nebulosa pré-história ou ao domínio exclusivo da antropologia. Os Tupinambá de Gabriel Soares alcançariam novamente um lugar de destaque no século XX, quando o eminente americanista Alfred Métraux os enfocou em seus estudos sobre as migrações, os movimentos proféticos e a religião tupi-guarani, juntando os antigos relatos com registros etnográficos modernos, sobretudo o importante estudo de Curt Nimuendaju sobre a escatologia dos Apapocuva-Guarani ${ }^{37}$. No entanto foi Florestan Fernandes que transformou os Tupinambá numa referência central à etnologia brasileira, pois sua meticulosa reconstituição e análise da organização social e do complexo da guerra-sacrifício-canibalismo entre os Tupinambá compõe um dos mais sofisticados exemplos de antropologia funcionalista em qualquer língua ${ }^{38}$. Mas os historiadores

\footnotetext{
${ }^{37}$ Métraux (1927 e 1979 [1928]). O estudo de Nimuendaju (1987 [1914]) apareceu inicialmente em Berlim em 1914 na Zeitschrift für Ethnologie, sendo finalmente publicado em português em 1987, com uma introdução muito esclarecedora de Eduardo Viveiros de Castro.

${ }^{38}$ Fernandes (1948 e 1980 [1952]). Quando elaborava seus estudos sobre os Tupinambá, Florestan desenvolveu uma tabela complexa que classificava os dados etnográficos extraídos das fontes dos séculos XVI e XVII. Se é verdade que esse autor retirou muitas observações pontuais de seu contex-
} 
continuaram a evitar os índios, como se a sentença de Varnhagen que condenava os índios à etnografia perpétua fosse ainda válida ${ }^{39}$.

Com efeito, ainda hoje a maioria dos historiadores parece acreditar que a história dos índios se resume à crônica de sua extinção. Esta perspectiva guarda um fundo de verdade, é claro, quando se considera o triste registro de guerras, epidemias, massacres e assassinatos que contribuíram para a dizimação de populações indígenas ao longo dos últimos cinco séculos. Para além deste rol de iniquidades, contudo, mesmo uma rápida releitura de documentos coloniais como os de Gabriel Soares de Sousa pode revelar uma história muito mais complexa, interessante e significativa do que aquela proposta pela tradição inaugurada por Varnhagen.

\section{Referências Bibliográficas}

ALDEN, Dauril. The Making of an Enterprise: the Society of Jesus in Portugal, its Empire, and Beyond, 1540-1750. Stanford University Press, Stanford, 1996.

BAYLY, Susan. Caste, Society and Politics in India from the Eighteenth Century to the Modern Age. (The New Cambridge History of India IV-3). Cambridge University Press, Cambridge, 1999.

BOCCARA, Guillaume. "Etnogénesis Mapuche: Resistencia y Restructuración entre los Indígenas del Centro-Sur de Chile (Siglos XVI-XVIII)”. Hispanic American Historical Review, 79:3, 1999, pp. 415-61.

BOEHRER, George C. A. "Some Brazilian Proposals to the Cortes Gerais, 1821-1823, on the Indian Problem”. In Atas do III Colóquio Internacional de Estudos Luso-Brasileiros, vol. 2, Lisboa, 1960, pp. 201-209.

to histórico mais abrangente, Florestan não ignorava o valor e as armadilhas presentes na crítica das fontes, o que acabou sendo sacrificado em função de sua opção metodológica (cf. Fernandes, 1975).

${ }^{39}$ Mesmo na notável História Geral da Civilização Brasileira, iniciada em 1960 sob a coordenação de Sérgio Buarque de Holanda, coube a Florestan Fernandes um capítulo preliminar sobre os antecedentes indígenas. O capítulo, no entanto, reproduziu o importante estudo sobre a "reação tupi à conquista" que, infelizmente, teve pouca repercussão nas discussões posteriores sobre a constituição da Colônia. 
CARDIM, S.J., Fernão. Tratados da Terra e da Gente do Brasil [1583-90]. Transcrição, organização e notas de Ana Maria de Azevedo. Comissão Nacional para a Comemoração dos Descobrimentos Portugueses, Lisboa, 1997.

CARNEIRO DA CUNHA, Manuela. Antropologia do Brasil. Brasiliense, São Paulo, 1986.

CARNEIRO DA CUNHA, Manuela. “Imagens de Índios do Brasil: o século XVI.” Estudos Avançados, 10, 1990, pp. 91-110.

CARNEIRO DA CUNHA, Manuela, org., 1992. História dos Índios no Brasil. Companhia das Letras, São Paulo, 1992.

CARVALHO, José Murilo de. "Introdução”. In LISBOA, João Francisco, Jornal de Timon, Companhia das Letras, São Paulo, 1995, pp. 5-29.

CASTELNAU-L'ESTOILE, Charlotte. Les Ouvriers d'une Vigne Stérile: les jésuites et la conversion des Indiens au Brésil, 1580-1620. Centre Culturel Calouste Gulbenkian e Comissão Nacional para a Comemoração dos Descobrimentos Portugueses, Paris e Lisboa, 2000.

COUTO DE MAGALHÃES, José Vieira. O Selvagem [1876]. Edusp/Itatiaia, São Paulo e Belo Horizonte, 1975.

CURTO, Diogo Ramada. "Representações de Goa: Descrições e Relatos de Viagem.” In PEREZ, R.M. e SARDO, S, orgs., Histórias de Goa. Museu Nacional de Etnologia, Lisboa, 1997, pp. 45-85.

DIAS, Maria Odila da Silva, 1974. O Fardo do Homem Branco: Southey, Historiador do Brasil, São Paulo, Companhia Editora Nacional (Brasiliana 344).

FERNANDES, Florestan. Organização Social dos Tupinambá. Progresso, São Paulo, 1948.

FERNANDES, Florestan, 1975. "Os Tupi e a Reação Tribal à Conquista". In FERNANDES, F., Investigação Etnológica no Brasil e Outros Ensaios. Vozes, Petrópolis, pp. 11-32.

FERNANDES, Florestan. Função Social da Guerra na Sociedade Tupinambá, Tupinambá [1952]. $3^{\text {a }}$ ed., Pioneira, São Paulo, 1980.

FRANCO, Francisco de Assis Carvalho. Dicionário de Bandeirantes e Sertanistas do Brasil. Comissão do IV Centenário, São Paulo, 1954.

GÂNDAVO, Pero Magalhães. Tratado da Terra do Brasil e História da Província de Santa Cruz [1576]. $2^{\mathrm{a}}$ ed., introdução de Capistrano de Abreu, notas de Rodolfo Garcia. Edusp/ Itatiaia, São Paulo e Belo Horizonte, 1980.

GRAÇA, Antônio Paulo. Uma Poética do Genocídio. Topbooks, Rio de Janeiro, 1998.

GUIMARÃES, Manoel Luís Salgado. "Naçãoe Civilizaçãonos Trópicos: o InstitutoHistóricoe Geográfico Brasileiro e o Projeto de uma História Nacional’. Estudos Históricos, 1, 1988, pp. 5-27. 
HEMMING, John. Amazon Frontier: the Defeat of the Brazilian Indians, Harvard University Press, Cambridge, 1987.

JANOTTI, Maria de Lourdes Mônaco. João Francisco Lisboa: Jornalista e Historiador. Editora Ática, São Paulo, 1977.

LACH, Donald. Asia in the Making of Europe. Volume 1. The Century of Discovery. 2 vols., University of Chicago Press, Chicago, 1965.

LISBOA, Karen Macknow. A Nova Atlântida de Spix e Martius: Natureza e Civilização na Viagem pelo Brasil (1817-1820). Hucitec, São Paulo, 1997.

MAGALHÃES, Domingos José Gonçalves de. "Os Indígenas do Brasil perante a História”, Revista do Instituto Histórico e Geográfico Brasileiro, 23, 1860, pp. 3-66.

MARTINS, José de Souza. "Um Documento Falso sobre a Conquista do Território dos Índios Goitacá no Século XVII”. Revista de Antropologia, 39:2, 1996, pp. 141-163.

MARTIUS, Carl F. P. von. "O Estado do Direito entre os Autóctones do Brasil [1838]”, in O Estado do Direito entre os Autóctones do Brasil. Tradução Alberto Löfgren. Edusp/ Itatiaia, São Paulo e Belo Horizonte, 1982, pp. 11-83.

MARTIUS, Carl F. P. von, 1982. "Como se deve escrever a história do Brasil [1845]", in $O$ Estado do Direito entre os Autóctones do Brasil. Tradução Alberto Löfgren. Edusp/ Itatiaia, São Paulo e Belo Horizonte, 1982, pp. 85-107.

MÉTRAUX, Alfred. Migrations historiques des Tupi-Guarani. Librairie Orientale et Américaine, Paris, 1927.

MÉTRAUX, Alfred. A Religião dos Tupinambás e suas Relações com a das demais Tribus TupiGuaranis [1928]. Tradução Estévão Pinto. 2 ed., Companhia Editora Nacional, São Paulo, 1979.

MONTEIRO, John M., "Tupis, Tapuias e a História de São Paulo. Revisitando a Velha Questão Guaianá." Novos Estudos Cebrap, 34, 1992, pp. 125-35.

MONTEIRO, John M. Negros da Terra: Índios e Bandeirantes nas Origens de São Paulo. Companhia das Letras, São Paulo, 1994.

MONTEIRO, John M. "The Crises and Transformations of Invaded Societies: Coastal Brazil in the Sixteenth Century". In SALOMON, F. e SCHWARTZ, S., orgs., The Cambridge History of the Native Peoples of the Americas. South America. Cambridge University Press, Cambridge, 1999, vol. 3, pt. 1, pp. 973-1023.

NEWITT, Malyn. A History of Mozambique. Indiana University Press, Bloomington, 1995. 
NIMUENDAJU, Curt. As Lendas de Criação e Destruição do Mundo como Fundamentos da Religião dos Apopocúva-Guarani [1914]. Tradução. C. Emmerich e E. V. de Castro. Hucitec/Edusp, São Paulo, 1987.

NOELLI, Francisco Silva. “As Hipóteses sobre o Centro de Origem e Rotas de Expansão dos Tupi”. Revista de Antropologia, 39:2, 1996, pp. 7-54.

ODÁLIA, Nilo. As Formas do Mesmo: ensaios sobre o pensamento historiográfico de Varnhagen e Oliveira Vianna. Editora da Unesp, São Paulo, 1997.

OLIVEIRA, Laura Nogueira. "Os Índios Bravos e o Sr. Visconde: os indígenas brasileiros na obra de Francisco Adolfo de Varnhagen”. Dissertação de Mestrado (inédita) em História, FAFICH-UFMG, 2000.

PEREZ, Rosa Maria. "Hinduísmo e Cristianismo em Goa: os Limites da Casta”. In PEREZ, R.M. e SARDO, S, orgs., Histórias de Goa. Museu Nacional de Etnologia, Lisboa, 1997, pp. 107-121.

REIS, José Carlos. "Varnhagen (1853-7): o Elogio da Colonização Portuguesa", Varia Historia, 17, 1997, pp. 106-31.

REVISTA. Revista da Exposição Anthropologica. Org. Mello Morais Filho. Typ. Ribeiro \& C., Rio de Janeiro, 1882.

RODRIGUES, José Honório. História da História do Brasil. $1^{a}$ Parte. Historiografia Colonial. Companhia Editora Nacional, São Paulo, 1979.

RODRIGUES, José Honório. História da História do Brasil, vol. 2, tomo 1: A Historiografia Conservadora. Companhia Editora Nacional, São Paulo, 1988.

ROUANET, Maria Helena. Eternamente em Berço Esplêndido: a fundação de uma literatura nacional. Siciliano, São Paulo, 1991.

SALVADOR, Frei Vicente do. História do Brasil, 1500-1627 [1627]. $7^{\mathrm{a}}$ ed., Edusp/Itatiaia, São Paulo e Belo Horizonte, 1982.

SCHWARCZ, Lilia K. Moritz. O Espetáculo das Raças: cientistas, instituições e questão racial no Brasil, 1870-1930. Companhia das Letras, São Paulo, 1993.

SCHWARTZ, Stuart B.. Segredos Internos: Engenhos e Escravos na Sociedade Colonial. Trad. Laura Teixeira Motta. Companhia das Letras, São Paulo, 1988.

SIDER, Gerald. "Identity as History: Ethnohistory, Ethnogenesis, and Ethnocide in the Southeastern United States". Identities, 1:1, 1994, pp. 109-122.

SOUSA, Gabriel Soares de. Tratado Descritivo do Brasil em 1587 [1587]. Companhia Editora Nacional/Edusp, São Paulo, 1971. 
SOUSA, Gabriel Soares de. "Capítulos de Gabriel Soares de Sousa contra os Padres da Companhia de Jesus que residem no Brasil [1587]". Anais da Biblioteca Nacional, 62, 1940, pp. 347-381.

SOUTHEY, Robert. History of Brazil. 3 vols., Longman, Hurst, Rees, Orme, and Brown, Londres, 1810-1819.

SUED BADILLO, Jalil. "The Island Caribs: New Approaches to Question of Ethnicity in the Early Colonial Caribbean". In WHITEHEAD, N., org., Wolves from the Sea: Readings in the Anthropology of the Native Caribbean. KITLV Press, Leiden, 1995, pp. 61-89.

VAINFAS, Ronaldo. A Heresia dos Índios: Catolicismo e Rebeldia no Brasil Colonial. Companhia das Letras, São Paulo, 1995.

VAINFAS, Ronaldo, org. Confissões da Bahia. Companhia das Letras, São Paulo, 1997.

VARNHAGEN, Francisco Adolfo de, Visconde de Porto Seguro. História Geral do Brasil [1854-57]. $7^{\text {a }}$ ed., 5 vols., Edusp/Itatiaia, São Paulo e Belo Horizonte, 1980.

VARNHAGEN, Francisco Adolfo de, Visconde de Porto Seguro. Os Índios e o Sr. Lisboa. Imprenta Liberal, Lima, 1867.

VIVEIROS DE CASTRO, Eduardo. "O Mármore e a Murta: Sobre a Inconstância da Alma Selvagem". Revista de Antropologia, 35, 1992, pp. 21-74.

WHITEHEAD, Neil. "Native American Cultures along the Atlantic Littoral of South America, 1499-1650". Proceedings of the British Academy, 81, 1993a, pp. 197-231.

WHITEHEAD, Neil. "Ethnic Transformation and Historical Discontinuity in Native Amazonia and Guayana, 1500-1900”, L'Homme, 126-128, 1993b, pp. 285-305.

WHITEHEAD, Neil. "The Historical Anthropology of Text. The Interpretation of Ralegh's Discovery of Guiana", Current Anthropology, 36:1, 1995, pp. 53-74. 